\title{
AB0, von Willebrand factor/Factor VIII and portal vein thrombosis in decompensated cirrhosis: too late to unmask the culprit?
}

Niccolò Bitto ${ }^{1}$, Giulia Tosetti ${ }^{2}$, Vincenzo La Mura ${ }^{1,2,3}$, Massimo Primignani ${ }^{2}$

Affiliations:

1 Fondazione IRCCS Ca' Granda, U.O.C. Medicina Generale Emostasi e Trombosi, Milano, Italy

2 Fondazione IRCCS Ca' Granda, CRC “A.M. e A. Migliavacca” per lo Studio e la Cura delle Malattie del Fegato Milano, Italy

3 Dipartimento di Scienze Biomediche per la Salute, Università degli studi di Milano, Milano, Italy

\section{Corresponding author}

Massimo Primignani, MD

Email: massimo.primignani@policlinico.mi.it

Word count (main text): 400

Total number of figures and tables: 1 table

Keywords: portal vein thrombosis, cirrhosis, von Willebrand factor, factor VIII, blood group

List of abbreviations: portal vein thrombosis (PVT), von Willebrand factor (VWF), factor VIII (FVIII), Thrombin Potential with/without thrombomodulin ratio (ETPr)

Conflicts of interest declaration: all authors declare no conflicts of interest involving this paper

Grants: This study was in part granted by the Bando Ricerca Corrente (Italian Minister of Health) 


\section{Dear Editor,}

We read with interest the paper from Scheiner et al., who investigated the influence of AB0 blood group on the risk of portal vein thrombosis (PVT) in patients with cirrhosis and wish to make comments. ${ }^{1}$ In the general population, the venous thrombosis risk is 2-4 fold increased in non-0 individuals, likely because of their higher von Willebrand factor (VWF) and factor VIII (FVIII) levels. ${ }^{2}$ In cirrhotics, VWF and FVIII are markedly increased. ${ }^{3}$ However, Scheiner et al. could not find association between non-0 group and PVT in 84947 cirrhotics listed for liver transplantation in the USA. In a second independent cohort of 411 cirrhotics (XX/XX Child $\mathrm{A} / \mathrm{BC})$, they found that the contribution of non-0 blood group on VWF variation was substantially smaller than in the general population and limited to patients with early stage cirrhosis, without further effect on FVIII, thus justifying the lack of association between non-0 blood group and PVT. To further explore this issue, we evaluated VWF:Ag, FVIII-activity, Protein C and Endogenous Thrombin Potential with/without thrombomodulin ratio (ETPr) in 69 patients with stable cirrhosis (Age 61 $\pm 12,70 \%$ male, Child A:41\%, Child B/C:59\%). VWF:Ag increased with cirrhosis severity, without further effect on FVIII. Non-0 vs 0 blood group had higher VWF:Ag $(+48 \%, \mathrm{p}<0.05)$ in Child A patients, but not in Child $\mathrm{B} / \mathrm{C}(+8 \%, \mathrm{p}=486)$ (Table 1). Interestingly, FVIII/VWF:Ag linear correlation was stronger in non-0 blood-group (Pearson correlation $\mathrm{R}=0.621, \mathrm{p}<0.001$ ) than in 0-blood group $(\mathrm{R}=0.110, \mathrm{p}=0.481$ ). These data confirm that the influence of blood-group on VWF:Ag/FVIII, observed in the general population, is maintained only in the early stages of cirrhosis, and suggests a disease-gradient effect from Child A to Child $\mathrm{B} / \mathrm{C}$ cirrhosis that overcomes genetics and modifies the correlation VWF/FVIII. FVIII levels, though increased, reached a plateau and did not parallel the further rises of VWF with cirrhosis severity. This notwithstanding, the ETPr increased with cirrhosis severity, as expected, driven by the progressive decrease of protein $\mathrm{C}^{4}{ }^{4}$ Thus, the FVIII/protein $\mathrm{C}$ ratio, rather than the VWF/FVIII levels, better signals the prothrombotic state of advanced cirrhosis. ${ }^{5}$ That is why, in our opinion, PVT often occurs in advanced cirrhosis, irrespective of AB0 group. Progressive endothelial dysfunction, paralleled by increasing VWF levels, and decreased portal flow velocity, both features of advanced cirrhosis, complete the Virchow triad of pathogenetic factors for PVT. Whether non-0 blood group could be a risk factor for PVT in early cirrhosis needs evaluation in large studies.

\section{References}

1. Scheiner B, Northup PG, Gruber AB, et al. The impact of ABO blood type on the prevalence of portal vein thrombosis in patients with advanced chronic liver disease. Liver Int. 2020. 
2. Albánez S, Ogiwara K, Michels A, et al. Aging and ABO blood type influence von Willebrand factor and factor VIII levels through interrelated mechanisms. J Thromb Haemost JTH. 2016;14:953-963.

3. Tripodi A, Primignani M, Mannucci PM, Caldwell SH. Changing Concepts of Cirrhotic Coagulopathy. Am J Gastroenterol. 2017;112:274-281.

4. Tripodi A, Primignani M, Lemma L, Chantarangkul V, Mannucci PM. Evidence that low protein C contributes to the procoagulant imbalance in cirrhosis. J Hepatol. 2013;59:265-270.

5. Praktiknjo M, Trebicka J, Carnevale R, et al. Von Willebrand and Factor VIII Portosystemic Circulation Gradient in Cirrhosis: Implications for Portal Vein Thrombosis. Clin Transl Gastroenterol. 2020;11:e00123.

Table: Hemostatic characteristics of patients by blood group and disease severity - continuous variables are expressed as mean and standard deviation.

\begin{tabular}{|c|c|c|c|c|c|c|c|c|c|}
\hline & \multirow[t]{2}{*}{$\begin{array}{c}\text { Overall } \\
(n=69)\end{array}$} & \multicolumn{4}{|c|}{$\begin{array}{c}\text { Child A } \\
(n=28)\end{array}$} & \multicolumn{4}{|c|}{$\begin{array}{c}\text { Child B/C } \\
(n=41)\end{array}$} \\
\hline & & Total & 0 & Non-0 & $* p$ & Total & 0 & Non-0 & $* p$ \\
\hline $\begin{array}{c}\text { VWF:Ag } \\
\text { (U/dl) }\end{array}$ & $386 \pm 167$ & $\begin{array}{c}310 \pm 14 \\
4\end{array}$ & $260 \pm 89$ & $\begin{array}{c}386 \pm 18 \\
2\end{array}$ & $\begin{array}{c}0.02 \\
1\end{array}$ & $\begin{array}{c}438 \pm 16 \\
3\end{array}$ & $\begin{array}{c}413 \pm 14 \\
9\end{array}$ & $\begin{array}{c}451 \pm 17 \\
1\end{array}$ & $\begin{array}{c}0.48 \\
6\end{array}$ \\
\hline $\begin{array}{l}\text { FVIII } \\
\text { (act\%) }\end{array}$ & $159 \pm 49$ & $166 \pm 37$ & $160 \pm 34$ & $175 \pm 40$ & 0.295 & $153 \pm 55$ & $149 \pm 62$ & $156 \pm 53$ & 0.711 \\
\hline $\begin{array}{c}\text { Protein C } \\
(\text { act } \%)\end{array}$ & $47 \pm 23$ & $60 \pm 20$ & $59 \pm 20$ & $62 \pm 22$ & $\begin{array}{c}0.66 \\
6\end{array}$ & $38 \pm 21$ & $39 \pm 28$ & $37 \pm 18$ & $\begin{array}{c}0.80 \\
8\end{array}$ \\
\hline $\begin{array}{c}\text { FVIII/Prote } \\
\text { in C }\end{array}$ & $437 \pm 4.3$ & $3.0 \pm 1.1$ & $3.1 \pm 1.2$ & $3.0 \pm 0.9$ & $\begin{array}{c}0.93 \\
7\end{array}$ & $5.8 \pm 5.4$ & $6.9 \pm 8.3$ & $5.2 \pm 3.1$ & $\begin{array}{c}0.47 \\
6\end{array}$ \\
\hline ETP Ratio & $\begin{array}{c}0.84 \pm 0.0 \\
8\end{array}$ & $\begin{array}{c}0.81 \pm 0 . \\
09\end{array}$ & $\begin{array}{c}0.81 \pm 0 \\
10\end{array}$ & $\begin{array}{c}0.81 \pm 0 \\
08\end{array}$ & $\begin{array}{c}0.69 \\
6\end{array}$ & $\begin{array}{c}0.86 \pm 0 \\
07\end{array}$ & $\begin{array}{c}0.83 \pm 0 \\
07\end{array}$ & $\begin{array}{c}0.87 \pm 0 . \\
07\end{array}$ & $\begin{array}{c}0.17 \\
9\end{array}$ \\
\hline
\end{tabular}

